\title{
Correction: Regression of primary cardiac angiosarcoma and metastatic nodules following propranolol as a single agent treatment
}

\author{
Dana C. Galván", Anoop P. Ayyappan², and Brad A. Bryan³ \\ ${ }^{1}$ Paul L. Foster School of Medicine, Texas Tech University Health Sciences Center, El Paso, TX, USA \\ 2 Department of Radiology, Texas Tech University Health Sciences Center, El Paso, TX, USA \\ ${ }^{3}$ Department of Biomedical Sciences, Texas Tech University Health Sciences Center, El Paso, TX, USA
}

Published: September 8, 2019

Copyright: Galván et al. This is an open-access article distributed under the terms of the Creative Commons Attribution License 3.0 (CC BY 3.0), which permits unrestricted use, distribution, and reproduction in any medium, provided the original author and source are credited.

This article has been corrected: A concentration in the Case Presentation section was corrected. The proper sentence is shown below.

\section{CASE PRESENTATION}

..."In May 2017, $40 \mathrm{mg}$ propranolol was administered daily and PET-CT scans were performed at regular intervals to assess the response of the tumor to propranolol."

Original article: Oncoscience. 2018 Oct 11;5(9-10):264-8

PMCID: PMC6231448 PMID: $\underline{30460329}$

DOI: 10.18632 /oncoscience. 472 